\title{
Leflunamide Induced Pneumonitis in Rheumatoid Arthritis - A Case Report and Review of Literature
}

\author{
*Mojumdar SK', Islam $M N^{2}$, Ahmedullah $A K^{3}$, Shahin $M A^{4}$, Hassan $M M^{5}$
}

\begin{abstract}
A 51 year old woman while treated on methotrexate (MTX) and leflunomide (LEF) for rheumatoid arthritis (RA), developed exertional breathlessness and undue tiredness followed by fever and cough, at her 11 years of suffering. Her respiratory symptoms developed around 12 weeks after leflunomide intake. She improved with steroid treatment. The Leflunomide (LEF) induced interstitial pneumonitis is an uncommon condition in absence of prior lung disease but potentially fatal. We report a case of Leflunomide (LEF) induced interstitial pneumonitis.
\end{abstract}

Key words: Rheumatoid arthritis, drug induced pneumonitis, methotraxate, leflunomide

\section{INTRODUCTION:}

Methotrexate (MTX) is the most commonly used disease modifying anti-rheumatic drug (DMARD) in RA.1 At low dose (<30mg), MTX has immunosuppressive and anti-inflammatory properties. 2 Other than therapeutic effect and well tolerability, one of the most serious infrequent side effects of this agent is MTX induced pneumonitis.3 Leflunomide (LEF) is another DMARD that have immunomodulatory effect had clinical outcome similar to MTX. It is also prescribed to manage RA since 1998.4 It has good safety profile but it can cause some side effects and

1. *Dr. Sumon Kanti Mojumdar, Phase B rheumatology student, Department of Rheumatology, Bangabandhu Sheikh Mujib Medical University, Shahbagh, Dhaka-1000, Bangladesh. Email: dskm.noa@gmail.com

2. Dr. Md. Nazrul Islam Professor of rheumatology, Department of Rheumatology, Bangabandhu Sheikh Mujib Medical University, Shahbagh, Dhaka-1000, Bangladesh.

3. Dr. Abul Khair Ahmedullah Assistant professor, Department of Rheumatology, Bangabandhu Sheikh Mujib Medical University, Shahbagh, Dhaka-1000, Bangladesh.

4. Dr. Md. Abu Shahin Associate professor, Department of Rheumatology, Bangabandhu Sheikh Mujib Medical University, Shahbagh, Dhaka-1000, Bangladesh.

5. Dr.Md. Masudul Hassan Department of Rheumatology, Bangabandhu Sheikh Mujib Medical University, Shahbag, Dhaka-1000, Bangladesh

${ }^{*}$ Corresponding Author pneumonitis is one of the reported one.5 We discuss here a patient who developed leflunomide induced pneumonitis. Who was on MTX for nine years.

\section{CASE REPORT:}

A 51-year-old woman has been suffering from RA since 2005. She was in remission for nine years with MTX at a dose of only $10 \mathrm{mg} /$ week. At 10th year she experienced a mild flare of RA and went into remission after escalation of MTX at $12.5 \mathrm{mg}$ weekly but failed to maintained remission and MTX doses was raised in subsequent flare gradually up to $25 \mathrm{mg}$ but complete remission could not be achieved. To achieve target $20 \mathrm{mg}$ leflunomide was added to MTX. After 3 months of MTX and leflunomide combination she again achieved remission (CDAI-2) and was relatively well until early May, 2016. But she suddenly developed fever, dry cough, progressive exertional shortness of breath and marked tiredness. Her physical findings were unremarkable. Few days later she got herself admitted in hospital for progressive deteriorations. Her respiratory rate was 30 breaths /minute, temperature was normal, pulse was 88 beats /minutes, BP was $120 / 80 \mathrm{~mm} \mathrm{Hg}$ and oxygen saturation was $90 \%$. She was evaluated with the clinical consideration of Pneumonia, acute asthma, pneumonitis, DPLD and/or pulmonary hypertension. Asthma, pneumonia, pulmonary hypertension were excluded after both clinical and laboratory evaluation.

Following investigations were done (table 1).

\section{Table 1: Baseline investigations}

\begin{tabular}{|l|l|}
\hline $\mathrm{Hb}$ & $11.4 \mathrm{gm} / \mathrm{dl}$ \\
\hline Total WBC & $6890 / \mathrm{mm} 3$ \\
\hline Eosinophilia & $13 \%$ \\
\hline ESR & $96 \mathrm{~mm}$ in 1 st hour \\
\hline CRP & $7.13 \mathrm{mg} / \mathrm{dl}$ \\
\hline X-ray chest P/A view & $\begin{array}{l}\text { Bilateral interstitial and alveolar } \\
\text { opacities in mid and basal region }\end{array}$ \\
\hline
\end{tabular}

$\mathrm{Hb}=$ Haemoglobin, $\mathrm{WBC}=$ white blood cell count, $\mathrm{ESR}=$ Erythrocyte sedimentation rate,

$\mathrm{CRP}=\mathrm{C}-$ reactive protein, $\mathrm{P} / \mathrm{A}=$ posterior/ anterior

Her hematological, renal and liver funcrion tests were normal with normal blood and urine culture. ECG, Echocardiography, spirometry and DLCO were normal. X-ray 
chest $\mathrm{P} / \mathrm{A}$ view showed bilateral interstitial and alveolar opacities in mid and basal region. HRCT of chest showed diffuse hyper attenuated areas with interstitial fine septal thickening intermixed with ground glass opacities in all segments of both lung fields predominantly in basal segments. (Figure-1A)
With that drug induced pneumonitis (most probably leflunomide) was suspected and both MTX and LEF were stopped. Prednisolone $40 \mathrm{mg} /$ day was started with other supportive treatments. Her fever started settling down and she symptomatically started to improve with lesser cough and breathlessness.

Figure- 1: HRCT of chest before (A) and after treatment (B) with steroid.

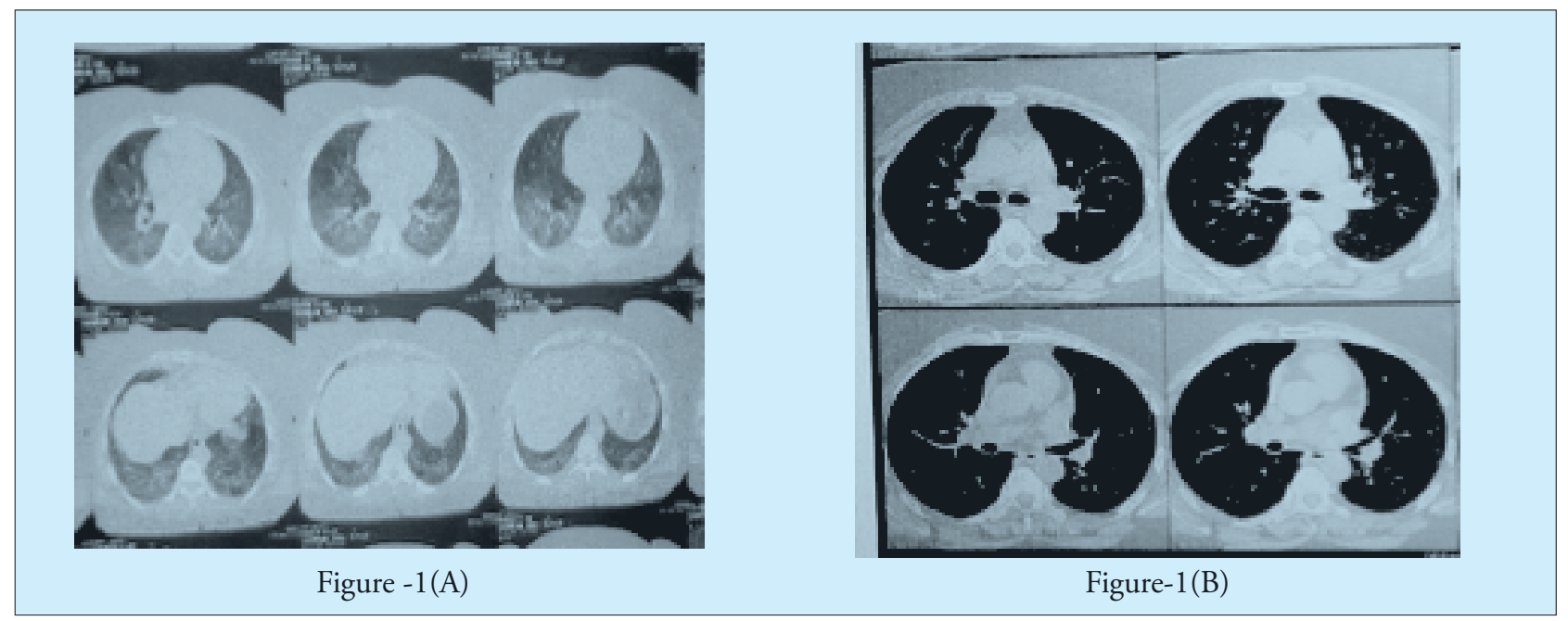

During first follow up after one month, she had no breathlessness or cough but complained of generalized weakness. Physical examination was unremarkable. Serum electrolytes, RBS and Serum creatinine were normal.

After two months of treatment there only was generalized weakness. Physical examination was unremarkable. Investigation reports revealed normalization of eosinophilia (01\%) and ESR (26 mm in 1st hour). Repeat HRCT showed few calcified foci with marked improvement of previous shadow. (Figure-1B)

\section{DISCUSSION:}

The active metabolite of Leflunomide is A77 1726 which inhibits dehydroorotate dehydrogenase. 6 In previous trials, LEF was proved to be as effective as MTX in improving joint symptoms and to halt the radiological progression of RA patients. 7 The relation between onset of pneumonitis and the initiation of LEF makes the strong possibility for the diagnosis of leflunomide induced pneumonitis (LEIP). Most LEIP patients had previous exposure with MTX and it is not surprising because LEF is used as second line therapy after MTX; but LEIP was also reported in MTX naïve patients. 8 Both MTX and LEF can induce pneumonitis either as monotherapy or in combination. In most of the cases the LEIP and MTX-P are indistinguishable. Currently, there is no available established clinical criteria that can distinguish LEIP from MTX-P but there are some differences in presentation between MTX-P and LEIP. LEIP symptoms usually appear acutely (median duration is 3 days and the range is 1-10 days), but in MTX-P symptoms appear sub-acutely (median duration is 14 days and the range is $1-56$ days) .9 MTX-P occurs within first twelve months of therapy but LEIP commonly occur within the first five months of starting treatment.10 In our patient, though she was on methotrexate but pneumonitis developed 3 months after starting leflunamide which suggest, according to this literature review, pneumonitis was due to leflunamide.

Many patients were on methotrexate prior to leflunomide, and methotrexate can be presumed as the cause of DPLD. While a patient is on methotrexate, development of pneumonitis soon after adding leflunomide suggests that leflunomide is responsible for pneumonitis and this are similar reports .11

LEIP incidence varies from $0.08 \%$ to $0.49 \%$ with a mortality of $0.7 \% .12$ LEIP can occur while treated with leflunomide alone or combined with MTX.13 Some author claimed that previous treatment with MTX augment the development of LEIP.14ר Ground glass appearance, bilateral interstitial nodular pattern, alveolar consolidation and honeycomb appearances are common findings in HRCT in LEIP.13 Which is consistent with our patient. Higher dose $(100 \mathrm{mg})$, age, body weight $<40 \mathrm{~kg}$ male sex, presence of previous lung injury, genetic predosposition, treatment history with MTX are the risk factors for LEIP.16

In this case, there was diffuse alveolar consolidation, ground glass densities, and septal thickenings, consistent with the 
findings reported in the literature. Especially discontinuation of LEF and MTX, faster clinical and radiological regression after steroid justified the diagnosis of LEIP in this case and plasma exchange could be an alternative method to clear the active metabolites. 15

\section{CONCLUSIONS:}

During the treatment period with leflunomide, we suggest for giving importance to the nonspecific pulmonary symptoms even in absence of physical signs as high index of suspicion and a prompt treatment with steroid might bring successful outcome in LEIP.

\section{REFERENCES:}

1. Chan V, Tett SE. Changes in use of disease-modifying antirheumatic drugs in Australia over the period 1992-2004. PharmacoepidemiolDrug Saf 2006; 15: 462-8.

2. Emery P, Breedveld FC, Lemmel EM, et al. A comparison of the efficacy and safety of leflunomide and methotrexate for the treatmentof rheumatoid arthritis. Rheumatology (Oxford) 2000; 39: 655-65.

3. Kinder AJ, Hassell AB, Brand J, Brownfield A, Grove M, Shadforth MF. The treatment of inflammatory arthritis with methotrexate in clinical practice: treatment duration and incidence of adverse drug reactions. Rheumatology 2005; 44: 61 .

4. Cohen S, Cannon GW, Schiff M et al. Two-year, blinded, randomized, controlled trial of treatment of active rheumatoid arthritis with leflunomide compared with methotrexate. Utilization of Leflunomide in the Treatment of Rheumatoid Arthritis Trial Investigator Group. Arthritis Rheum 2001; 44:1984-92.

5. Sakai F, Noma S, Kurihara Y, Yamada H, Azuma A, Kudoh S, et al. Leflunomide-related lung injury in patients with rheumatoidarthritis. Mod Rheumatol 2005; 15:173-9.

6. Chong AS, Huang W, Liu W et al. In vivo activity of leflunomide: pharmacokinetic analyses and mechanism of immunosuppression. Transplantation 1999; 68:100-9.

7. Cohen S, Cannon GW, Schiff M et al. Two-year, blinded, randomized, controlled trialof treatment of active rheumatoid arthritis with leflunomide compared with methotrexate.Utilization of Leflunomide in the Treatment of Rheumatoid Arthritis TrialInvestigator Group. Arthritis Rheum 2001; 44:1984-92.

8. Otsuka T, Koyama T, Ohtani R et al. Leflunomide-induced lung injury that developedafter its withdrawal, coinciding with peripheral blood lymphocyte count decrease.Mod Rheumatol 2008; 18:96-9.

9. Chikura B, Sathi N, Lane S, Dawson JK. Variation of immunological response in methotrexate-induced pneumonitis. Rheumatology 2008; 47:1647-50.

10. Savage RL, Highton J, Boyd IW, Chapman P. Pneumo- nitis associated with leflunomide:a profile of New Zealand and Australian reports. Intern Med J 2006; 36:162-9.

11. Savage RL, Highton J, Boyd IW, Chapman P. Pneumonitis associatedwith leflunomide: A profile of new zealand and australian reports.Intern Med J 2006;36:162-169.

12. Kelly C. Leflunomide and the lung. Rheumatology (Oxford) 2009; 48:1017-8.

13. Carloni A, Piciucchi S, Giannakakis K, Nori G, Zobel BB, Poletti V. Diffuse alveolar hemorrhage after leflunomide therapy in a patient with rheumatoidarthritis. J Thorac Imaging 2008; 23: 57-9.

14. Chikura B, Lane S, Dawson JK. Clinical expression of leflunomide-induced pneumonitis. Rheumatology (Oxford) 2009; 48: 1065-8.

15. Inokuma S, Sato T, Sagawa A, Matsuda T, Takemura T, Ohtsuka T,Saeki Y,TakeuchiT, SawadaT. Proposals for leflunomide use to avoidlung injury in patients with rheumatoid arthritis. Mod Rheumatol 2008;18:442-446.

16. Güzel, A., Köksal, N., Gök, A., \& Elmalı, M. Leflunomide-Induced Interstitial Lung Disease: A Case Report. Eurasian J Pulmonol 2015; 17: 67-9. 